EVIDENCE BASED PUBLIC HEALTH POLICY AND PRACTICE

\title{
Work and health in a contemporary society: demands, control, and insecurity
}

\author{
R M D'Souza, L Strazdins, L L-Y Lim, D H Broom, B Rodgers
}

J Epidemiol Community Health 2003;57:849-854

See end of article for authors' affiliations

....................

Correspondence to:

Dr R M D'Souza, National

Centre for Epidemiology and Population Health, The Australian National University, Canberra, ACT 0200, Australia; rennie.dsouza@anu. edu.au

Accepted for publication 13 April 2003

\begin{abstract}
Objective: To examine independent associations of job strain (high demands and low control) and job insecurity with mental and physical health outcomes.

Design: Cross sectional general population study conducted in 2000 using a self completed questionnaire. Setting: Two adjoining cities in south east Australia.

Subjects: 1188 employed professionals, aged 40-44 years, 55\% ( $n=655)$ male.

Main outcome measures: Depression, anxiety, physical, and self rated health (SRH).

Results: Adverse job conditions were relatively prevalent as $23 \%$ of the sample reported high job strain, while $7.3 \%$ and $23 \%$ reported high and moderate job insecurity respectively. Associations between job conditions and health persisted after adjustment for gender, education, marital status, employment status, major life events, and negative affectivity (personality). When adjusted for job strain, high job insecurity was independently associated with a greater than threefold increase in odds for poor SRH, depression and anxiety (OR (95\% confidence intervals) poor SRH: 3.72 (1.97 to 7.04) depression: 3.49 (1.90 to 6.41), anxiety: 3.29 (1.71 to 6.33)), and a twofold increase for physical health 2.19 (1.21 to 3.95). High job strain also showed significant independent associations with depression: 2.54 (1.34 to.4.75) and anxiety: 3.15 (1.48 to 6.70).

Conclusion: In this relatively privileged socioeconomic group, insecure employment and high job strain showed independent, consistent, and strong associations with physical and mental health. These adverse job conditions are on the increase, particularly insecure employment, and the influence of these two work conditions are an important focus for future public health research and their prevalence and impact should be examined in other occupations.
\end{abstract}

$\mathrm{F}$ or over two decades, researchers ${ }^{1-3}$ have investigated the effects of job demands and job control on wellbeing. Job control refers to employees' ability to make decisions about how and when they perform their work as well as the extent to which their job entails using and developing their skills. Job demands encompasses the amount and pace of work. ${ }^{4}$ The combination of high job demands and low control, termed job strain, has been linked to a wide range of mental and physical health outcomes. ${ }^{5-7}$ Poor job control appears to be prevalent and associated with lower occupational status. ${ }^{8}$

Work conditions are changing as a result of globalisation and increasing competition. One change has been the growth of insecure or casual employment. For example, casual employees now constitute $27 \%$ of the Australian workforce, compared with $19 \%$ a decade ago. ${ }^{9}$ In the context of downsizing and more temporary or short term contract work, many employees may consider their jobs insecure.

Unlike job demands and control, less research has examined the health impact of insecurity. However, studies indicate that job insecurity could also affect health. ${ }^{7}{ }^{10-12} \mathrm{Job}$ insecurity involves both the threat of job loss, and uncertainty regarding future employment. Threat of job loss has also been associated with increases in self reported morbidity, serum cholesterol, depression, and anxiety. ${ }^{13-15}$

The aim of this study is to examine the extent to which job strain and job insecurity are associated with mental and physical health outcomes. We test whether job strain and insecurity are independently associated with employee health. Because adverse working conditions are associated with low education and income ${ }^{8}$ we have restricted our sample to comparatively advantaged employees-that is, managers and professionals. We expect this sample to be those least vulnerable to work related stress, which along with adjustment for other key confounding factors, will supply a conservative test of the health impact of job strain and insecurity.

\section{METHODS AND SAMPLE}

The PATH 40+ (Personality and Total Health) Through Life Project is a cross sectional study of 40 to 44 year old adults conducted by the Centre for Mental Health Research, The Australian National University. Firstly, 9033 residents of two south east cities of Australia aged 40 to 49 were identified from electoral rolls.* Letters were then sent inviting participation if they were aged 40 to 44 on the 1 January 2000. Of these, 4222 were outside of the age range, 281 had moved out of the area, 612 could not be traced, and 1389 refused to participate. The remaining 2530 (64.6\% of those within age range) were then interviewed using hand held computers to respond directly to the survey questions. Occupations were coded according to the Australian Standard Classification of Occupations (ASCO) (second edition) based on job title, main tasks performed, and industry of employer. While the ASCO can be coded to a very detailed 6 digit level, we coded ours to the four digit level. ${ }^{16}$ For this study, the sample was restricted to currently employed and self employed managers and professionals (ASCO codes 1000 through to 2549) for whom we had complete data on study factors and outcomes. Eighty one unemployed people and nine with incomplete data were excluded, resulting in a total population of 1188. Approval for this study was obtained from the human research ethics committee of the Australian National University.

*Australian electoral rolls provide virtually complete lists of voting age adults, excepting those of unsound mind, serving a prison sentence of five years or more, or convicted of treason or treachery 


\section{Key points}

- Adverse work conditions are associated with poor health, particularly mental health

- Both job strain (high demands and low control) and job insecurity were independently associated with poor health outcomes.

- The health impact of work is independent of personality.

- Even in a relatively advantaged sample, fear of job loss and a sense of job insecurity may have potent health impacts.

\section{Outcome variables}

Four health outcomes were analysed: depression, anxiety, physical and self rated health (SRH). Depression and anxiety were assessed using Goldberg's 9 item Scales. ${ }^{17}$ Items were summed to give total scores on each scale ranging from 0 to 9. These scales have been extensively validated in community samples and have high internal consistency (Cronbach's $\alpha=0.78$ for depression and 0.79 for anxiety). The short form SF 12 Physical Health Summary Scale is comprised of a 12 item subset of the SF-36 ${ }^{18}$ and assesses physical functioning, pain, and impairment.

Self rated health (SRH) was measured by a single question shown to predict later morbidity and mortality. ${ }^{19}$ Participants rated their health as either excellent, very good, good, fair, or poor.

\section{Exposure measures}

Job demands and job control were measured by items used by Bosma ${ }^{2}$ in the UK Whitehall study. Job demands (four items) assessed the intensity and pace of work while job control (15 items) assessed skill discretion and decision making. There were four response categories for these 19 items (often, sometimes, rarely, and never). Insecurity about current job was assessed by a single item with four response categories (very secure, secure, moderately secure, and not at all secure).

\section{Sociodemographic factors and confounders}

Demographic measures from the self completed questionnaire included gender, education, marital status, employment status (full time or part time), and employment position representing managerial, supervisory, or non-management roles (the latter was self assessed by respondents based on their current job responsibilities). Major life events controlled for in the analysis were a major illness, death of a close family relative and relationship problems and if they experienced any financial hardship in the past six months.

Sensitivity to negative stimuli, also termed neuroticism or negative affectivity is known to correlate with both perceptions of work stress and with self reported health outcomes. ${ }^{20}$ To adjust for potential confounding, this personality trait was assessed with the seven item behavioural inhibition system (BIS) scale ${ }^{21}$ (Cronbach's $\alpha=0.78$ for BIS).

\section{Statistical methods}

Job demands and control were dichotomised at the median (high and low), and the two variables were combined to measure the degree of job strain. High strain was defined as low job control and high job demands. Passive jobs were defined as the combination of low job control and low job demands; active jobs were those with high job control with

\section{Policy implications}

- The potential impact of job strain and job insecurity on employee health warrants attention by governments, management, and unions formulating industrial relations policies and agreements.

high job demands and low strain jobs were defined by high job control with low job demands.

Secure and very secure job categories were combined into one group indicating low job insecurity; moderately secure and not at all secure jobs were coded as moderate and high job insecurity; hence job insecurity was classified into three categories: low, moderate, and high.

Cut offs closest to the upper octile were used to dichotomise the continuous scores of depression and anxiety, the nearest cut offs identifying $10 \%$ as depressed (between 5 and 6) and $8.3 \%$ as anxious (between 7 and 8). Scores for SF12 physical health were dichotomised at the lower octile, classifying $12.5 \%$ as having physical health problems. SRH was dichotomised between what we have called good and poor health $($ good $=$ responses: excellent, very good, or good; poor $=$ fair or poor)

For each outcome variable, we compared those with low job strain with those reporting high, active or passive job strain, and those with low job insecurity with those reporting high or moderate job insecurity using the $\chi^{2}$ statistic at conventional levels of significance $(p<0.05)$. Three sets of multivariate logistic analyses were performed: strain only, insecurity only, and strain and insecurity together in the same model. Education, gender, marital status, employment status, major life events, and negative affectivity (BIS) treated as a continuous variable were covariates in all the analyses. All the statistical analyses were conducted using SPSS.

\section{RESULTS}

The sample $(\mathrm{n}=1188)$ included a range of different professions: managers (34\%), information technology specialists (16\%), teachers $(10.8 \%)$, nurses $(4.4 \%)$, other business professionals $(4.4 \%)$, lawyers $(2 \%)$, social welfare officers $(2 \%)$, and doctors ( $1 \%)$. Just over half $(55 \%)$ were men, two thirds $(67 \%)$ had tertiary education and more than three quarters were married (81\%) (table 1). Most (84\%) were employed full time and most $(89 \%)$ worked in organisations with more than 25 employees. Government agencies employed $60 \%$ of respondents, and $12 \%$ were self employed. Of the salaried professionals, $50 \%$ described themselves as being in managerial positions while a third held neither managerial nor supervisory roles. The average BIS score for negative affectivity was 20.66 (SD 3.28), comparable to Australian norms. ${ }^{22}$

\section{Job strain}

Overall, about one quarter $(n=274,23 \%)$ of participants ${ }^{66}$ were classified as having "high" job strain. High job strain was associated with gender and personality (high negative affectivity) (fig lA). Full time workers, those employed by government or non-government organisations, those in supervisory positions and those who worked in larger organisations were also more likely than others to experience high job strain (fig 1B).

Associations of job strain with mental, physical and SRH are shown in table 2A. Passive and high strain jobs were associated with, depression, anxiety, and SRH $(\mathrm{p}<0.01)$ (table 2). Adjustment for gender, marital status, education, 
Table 1 Sociodemographic and employment characteristics of the sample

\begin{tabular}{|c|c|c|}
\hline & $n=1188$ & $\%$ \\
\hline \multicolumn{3}{|l|}{ Gender } \\
\hline Men & 655 & 55.1 \\
\hline Women & 533 & 44.9 \\
\hline \multicolumn{3}{|l|}{ Education } \\
\hline Tertiary education & 796 & 67.0 \\
\hline Diploma (diploma/undergraduate or trade certificate) & 262 & 22.1 \\
\hline School (some primary or secondary education) & 130 & 10.9 \\
\hline \multicolumn{3}{|l|}{ Marital status } \\
\hline Couple (married/defacto) & 956 & 80.5 \\
\hline Separated (separated/divorced/widowed) & 139 & 11.7 \\
\hline Single & 93 & 7.8 \\
\hline \multicolumn{3}{|l|}{ Employment status } \\
\hline Full time & 955 & 83.8 \\
\hline Part time & 193 & 16.2 \\
\hline \multicolumn{3}{|l|}{ Employed by } \\
\hline Government agency & 715 & 60.2 \\
\hline Profit making agency & 213 & 17.9 \\
\hline Another organisation & 113 & 9.5 \\
\hline Self employed/in business practice for oneself & 147 & 12.4 \\
\hline \multicolumn{3}{|l|}{ Size of employment agency* } \\
\hline 1-9 members & 58 & 5.6 \\
\hline $10-24$ & 60 & 5.8 \\
\hline $25+$ & 923 & 88.6 \\
\hline \multicolumn{3}{|l|}{ Position* } \\
\hline Managerial & 517 & 49.7 \\
\hline Supervisory & 174 & 16.7 \\
\hline Non-management & 350 & 33.6 \\
\hline \multicolumn{3}{|l|}{ BIS scoret } \\
\hline Mean score (SD) & 20.66 (3. & \\
\hline Median & 21.00 & \\
\hline Range & (9-28) & \\
\hline
\end{tabular}

employment status, major life events, and negative affectivity reduced these gradients somewhat, particularly for physical and SRH, but strong associations were still evident for high job strain and mental health outcomes (OR depression $=2.84,95 \%$ confidence intervals ( 1.53 to 5.27 ) and OR anxiety $=3.42(1.62$ to 7.19$))$.

\section{Job insecurity}

High and moderate job insecurity were reported by $7 \%$ $(\mathrm{n}=87)$ and $23 \%(\mathrm{n}=273)$ of the sample respectively. In addition to marital status, negative affectivity showed an association with job insecurity (fig 2A). Part time workers, those self employed, in non-management positions or

A
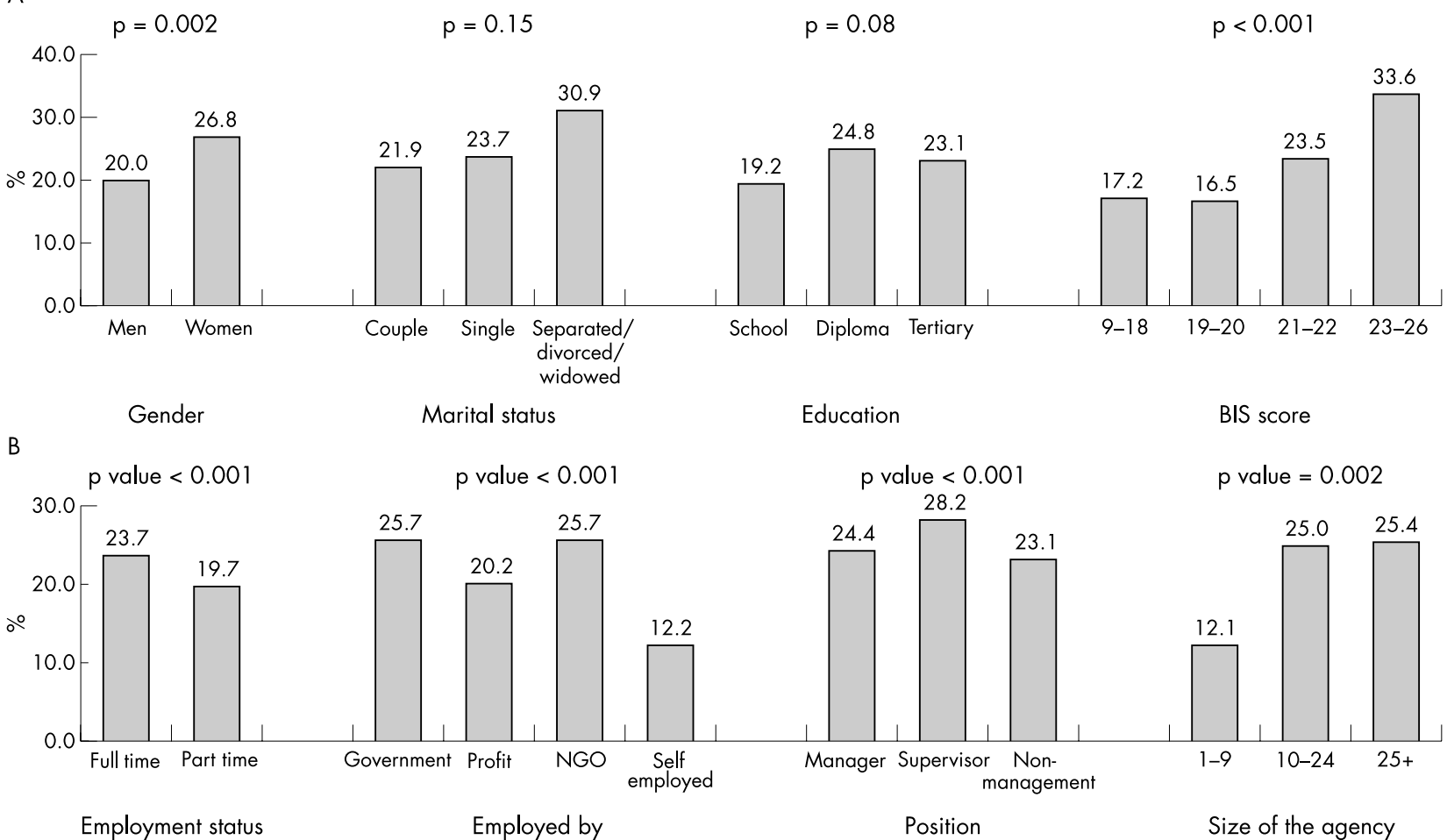

Figure 1 High job strain by (A) demographic and (B) employment characteristics. 
Table 2 (A) Job strain, (B) job insecurity: unadjusted and adjusted odds ratios for depression, anxiety, poor physical and overall health

\begin{tabular}{|c|c|c|c|c|c|c|c|}
\hline (A) Job strain & Job strain & $\mathrm{N}$ & $\%$ & Unadjusted OR $(95 \% \mathrm{Cl})$ & p Value & Adjusted $\mathrm{OR}^{*}(95 \% \mathrm{Cl})$ & p Value \\
\hline \multirow[t]{4}{*}{ Depression } & Low & 347 & 4.6 & 1.0 & & 1.0 & \\
\hline & Active & 243 & 8.2 & 1.86 (0.94 to 3.66$)$ & 0.07 & $1.68(0.84$ to 3.39$)$ & 0.15 \\
\hline & Passive & 324 & 11.7 & 2.75 (1.50 to 5.03$)$ & 0.001 & 2.06 (1.10 to 3.84$)$ & 0.02 \\
\hline & High & 274 & 16.4 & 4.07 (2.24 to 7.37$)$ & $<0.001$ & 2.84 (1.53 to 5.27$)$ & 0.001 \\
\hline \multirow[t]{4}{*}{ Anxiety } & Low & 347 & 2.9 & 1.0 & & 1.0 & \\
\hline & Active & 243 & 7.8 & 2.86 (1.31 to 6.26$)$ & 0.009 & 2.30 (1.02 to 5.23$)$ & 0.05 \\
\hline & Passive & 324 & 9.6 & $3.57(1.72$ to 7.40$)$ & 0.001 & $2.57(1.20$ to 5.49$)$ & 0.02 \\
\hline & High & 274 & 14.2 & 5.59 (2.74 to 11.42 ) & $<0.001$ & $3.42(1.62$ to 7.19$)$ & 0.001 \\
\hline \multirow[t]{4}{*}{ Physical health } & Low & 347 & 10.4 & 1.0 & & 1.0 & \\
\hline & Active & 243 & 11.9 & 1.17 (0.70 to 1.97$)$ & 0.55 & $1.06(0.62$ to 1.83$)$ & 0.82 \\
\hline & Passive & 324 & 10.8 & 1.05 (0.64 to 1.71$)$ & 0.86 & $0.80(0.48$ to 1.36$)$ & 0.39 \\
\hline & High & 274 & 17.5 & 1.84 (1.15 to 2.92$)$ & 0.01 & $1.36(0.83$ to 2.30$)$ & 0.22 \\
\hline \multirow[t]{4}{*}{ Self rated health } & Low & 347 & 4.6 & 1.0 & & 1.0 & \\
\hline & Active & 243 & 5.8 & $1.27(0.61$ to 2.64$)$ & 0.53 & $1.10(0.51$ to 2.35$)$ & 0.81 \\
\hline & Passive & 324 & 8.6 & 1.96 (1.04 to 3.69$)$ & 0.04 & $1.46(0.76$ to 2.81$)$ & 0.26 \\
\hline & High & 274 & 11.3 & 2.64 (1.41 to 4.93$)$ & 0.002 & 1.85 (0.96 to 3.54$)$ & 0.07 \\
\hline \multicolumn{8}{|l|}{ (B) Job insecurity } \\
\hline \multirow[t]{3}{*}{ Depression } & Low & 828 & 6.2 & 1.0 & & 1.0 & \\
\hline & Moderate & 273 & 16.1 & 2.93 (1.91 to 4.50$)$ & $<0.001$ & 2.73 ( 1.74 to 4.27 ) & $<0.001$ \\
\hline & High & 87 & 27.6 & $5.80(3.35$ to 10.04$)$ & $<0.001$ & 3.78 (2.06 to 6.91$)$ & $<0.001$ \\
\hline \multirow[t]{3}{*}{ Anxiety } & Low & 828 & 5.4 & 1.0 & & 1.0 & \\
\hline & Moderate & 273 & 12.1 & 2.39 (1.49 to 3.84 ) & $<0.001$ & 2.07 (1.25 to 3.43 ) & 0.004 \\
\hline & High & 87 & 24.1 & 5.54 (3.11 to 9.85$)$ & $<0.001$ & 3.55 (1.85 to 6.81$)$ & 0.001 \\
\hline \multirow[t]{3}{*}{ Physical health } & Low & 828 & 10.5 & 1.0 & & 1.0 & \\
\hline & Moderate & 273 & 14.3 & 1.42 (0.95 to 2.13$)$ & 0.09 & $1.34(0.88$ to 2.05$)$ & 0.18 \\
\hline & High & 87 & 25.3 & 2.88 (1.69 to 4.91$)$ & $<0.001$ & 2.23 (1.24 to 4.00$)$ & 0.007 \\
\hline \multirow[t]{3}{*}{ Self rated health } & Low & 828 & 5.3 & 1.0 & & 1.0 & \\
\hline & Moderate & 273 & 8.8 & 1.72 (1.02 to 2.88 ) & 0.04 & $1.48(0.87$ to 2.52$)$ & 0.15 \\
\hline & High & 87 & 24.1 & $5.67(3.18$ to 10.10$)$ & $<0.001$ & $3.96(2.10$ to 7.46$)$ & $<0.001$ \\
\hline
\end{tabular}

working in smaller organisations were more likely to experience high job insecurity (fig $2 \mathrm{~B}$ ).

Job insecurity was strongly associated with all four health outcomes (table 2B). These associations persisted after adjusting for gender, education, marital status, employment status, major life events, and negative affectivity. The effect was most marked for depression and SRH, with high job insecurity increasing the odds fourfold in the adjusted model (OR depression $=3.78$ (2.06 to 6.91), OR poor $\mathrm{SRH}=3.96$ (2.10 to 7.46$)$ ).

Life events were unrelated to reports of job strain or insecurity, with the exception that those with insecure jobs were more likely to have experienced recent bereavement $(\mathrm{p}<0.002)$ (data not shown).

A

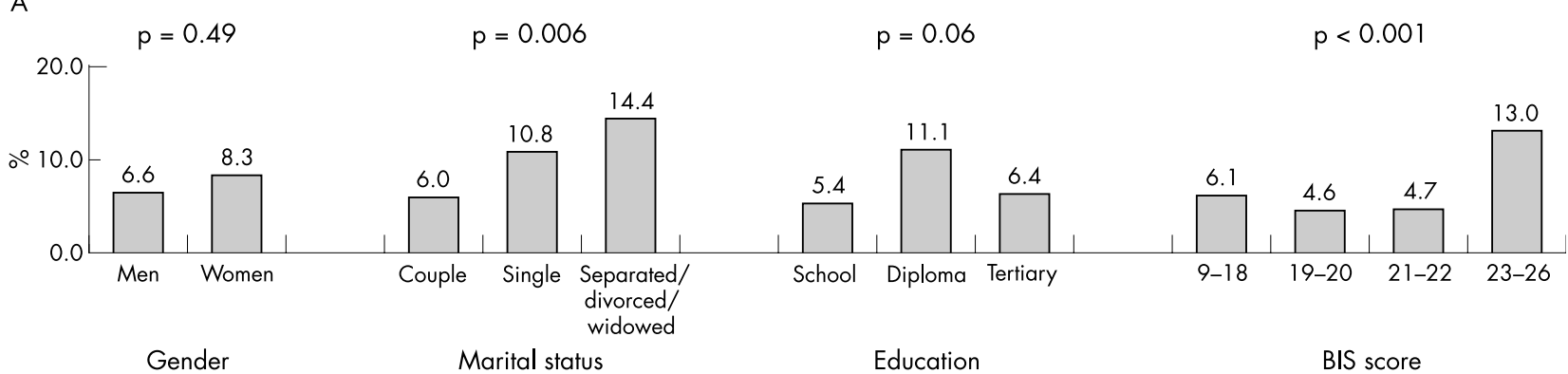

B

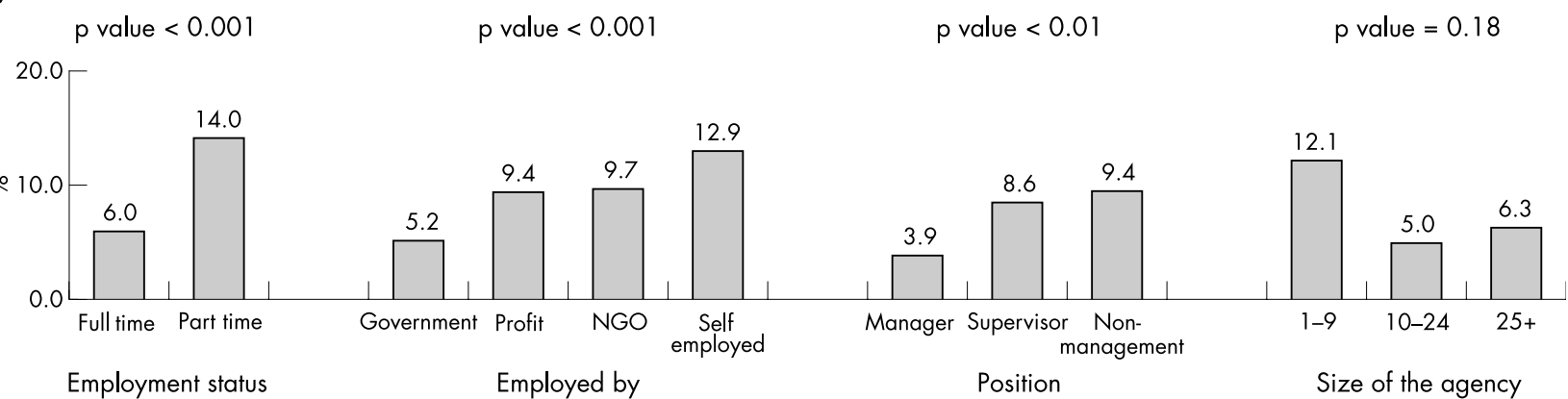

Figure 2 High job insecurity by (A) demographic and (B) employment characteristics. 
Table 3 Adjusted* odds ratios and $95 \% \mathrm{Cl}$ for depression, anxiety, poor physical and overall health by job strain and job insecurity modelled together

\begin{tabular}{|c|c|c|c|c|c|c|c|c|}
\hline & Depression & $p$ Value & Anxiety & $\mathrm{p}$ Value & Global physical health & p Value & Self rated health & p Value \\
\hline & OR (95\% Cl) & & OR (95\% Cl) & & OR (95\% Cl) & & OR (95\% Cl) & \\
\hline \multicolumn{9}{|l|}{ Job strain } \\
\hline Low & 1.0 & & 1.0 & & 1.0 & & 1.0 & \\
\hline Active & $1.62(0.80$ to 3.30$)$ & 0.18 & $2.29(1.00$ to 5.24$)$ & 0.05 & $1.04(0.60$ to 1.80$)$ & 0.88 & 1.09 (0.51 to 2.34$)$ & 0.83 \\
\hline Passive & 1.83 (0.97 to 3.44$)$ & 0.06 & $2.38(1.01$ to 5.13$)$ & 0.03 & 0.76 (0.45 to 1.27 ) & 0.29 & $1.37(0.71$ to 2.66$)$ & 0.35 \\
\hline $\begin{array}{l}\text { High } \\
\text { Job insecurity }\end{array}$ & 2.54 (1.35 to 4.75$)$ & 0.004 & $3.15(1.48$ to 6.70$)$ & 0.003 & $1.28(0.78$ to 2.10$)$ & 0.34 & 1.66 (0.86 to 3.22$)$ & 0.13 \\
\hline Low & 1.0 & & 1.0 & & 1.0 & & 1.0 & \\
\hline Moderate & 2.60 (1.66 to 4.08 ) & $<0.001$ & $1.99(1.20$ to 3.29$)$ & 0.008 & 1.37 (0.89 to 2.09 ) & 0.15 & 1.43 (0.84 to 2.44 ) & 0.19 \\
\hline High & 3.49 (1.90 to 6.41$)$ & $<0.001$ & 3.29 (1.71 to 6.33 ) & $<0.001$ & $2.19(1.21$ to 3.95$)$ & 0.009 & 3.72 (1.97 to 7.04 ) & $<0.001$ \\
\hline
\end{tabular}

*Adjusted for gender, education, marital status, negative affectivity, part time employment, serious illness, death of a close family relative, and relationship problems.

\section{Job insecurity after controlling for job strain}

Comparing high job insecurity with high job strain we found the following proportions reporting depression $(28 \% v 16 \%)$, anxiety $(24 \% \vee 14 \%)$, poor physical health $(25 \% \vee 18 \%)$, and poor SRH $(24 \% \quad v \quad 11 \%)$. Although job strain and job insecurity were associated they were weakly correlated (polychoric correlation $=0.22$ with standard error 0.03), indicating that the two measures refer to different aspects of job conditions.

Both work variables also show important independent associations with health (table 3 ). Multiplicative interactions between job strain and job insecurity were examined, however, given the large number of terms and small numbers in some categories, models became unstable. Therefore, only the main effects models are reported. Independent associations between health outcomes, job strain and job insecurity were observed even after including the major confounders in the model. Independent of the associations of job strain, people with high job insecurity had nearly four times the odds for depression $(\mathrm{OR}=3.49$ ( 1.90 to 6.41$))$ and poor SRH $(\mathrm{OR}=3.72$ (1.97 to 7.04$))$. A slightly smaller odds ratio was observed for anxiety (OR $=3.29$ (1.71 to 6.33)) and poor physical health $(\mathrm{OR}=2.19(1.21$ to 3.95$))$. Even those employees reporting moderate job insecurity were at increased risk for depression and anxiety. High job strain also showed significant independent associations with depression (OR 2.54 (1.35 to 4.75) and anxiety (OR 3.15 (1.48 to 6.70). Even when controlled for financial hardship, high job insecurity still showed significant associations with physical and mental health outcomes (data not shown).

\section{DISCUSSION}

Job strain and job insecurity are distinctive work conditions, and both are independently associated with poor health particularly mental health. These job conditions are comparatively common and, at least in the case of insecurity, will become more so if current labour market trends continue. Neither gender, education, marital status, major life events, part time or full time employment status, financial hardship, nor personality explained the associations. The associations between job strain and mental health are consistent with other studies. ${ }^{13}$ Furthermore, our results extend job strain research by showing that job insecurity has strong, independent associations with health outcomes including physical and SRH as well as anxiety and depression.

These results raise several questions. It is unclear what the intensity and duration of job strain must be before a person's health is affected..$^{23}$ It is possible that workers with either mental or physical health problems may leave the workforce or move to jobs with lower strain, creating a selection bias and underestimation of the effects of job strain. ${ }^{3}$
Furthermore, we could not estimate whether employees' perception of job insecurity was a result of illness, rather than a cause, although we did adjust for recent major illness in our analyses. Nor did we measure other work stressors such as poor workplace support, which might compound effects on health. As in all observational studies, the imperfect measurement of some covariates and the omission of others from data collection may bias the estimate of association between the main risk factors and outcomes of interest. Finally, the cross sectional design does not allow us to examine the possible interplay over time between job strain, job insecurity and health. We cannot assume a direct causal influence of these adverse work conditions on health.

The changing nature of work has implications for societies and for workplaces. Both job strain and insecurity are associated with sickness absence, which affects productivity. ${ }^{24}$ In Australia, mental health problems account for the greatest population burden of disability, ${ }^{26}$ and our results indicate that poor mental health is associated with adverse job conditions. The results of this study raise concerns about the adverse health effects in people who might be experiencing both high job strain and high job insecurity. As the labour market becomes more globalised and competitive, employees are more likely to encounter these two work conditions simultaneously. Therefore the influence of work on health is an important focus for future population health research, policy, and intervention.

\section{ACKNOWLEDGEMENTS}

Rennie M D'Souza, Lyndall Strazdins, Dorothy H Broom and Lynette L-Y Lim were funded by the National Centre for Epidemiology and Population Health, Australian National University and Bryan Rodgers by the Centre for Mental Health Research, Australian National University. We also acknowledge the contributions made by the following chief investigators of the PATH study: Anthony Jorm, Helen Christensen, Kaarin Anstey, and Kathy Griffiths, and Keith Dear.

\section{CONTRIBUTORS}

Rennie M D'Souza contributed to the conception of the study, analysis, interpretation of the results and writing of successive drafts of the paper, final approval of the version to be published and will be the guarantor for this paper. Lyndall Strazdins contributed to the conception of the study, interpretation of the results, writing of successive drafts of the paper, and final approval of the version to be published. Lynette Lim contributed to conception of the study, interpretation of the results and editing successive drafts of the paper and final approval of the version to be published. Dorothy Broom contributed to conception of the study, interpretation of the results, editing successive drafts of the paper and final approval of the version to be published. Bryan Rodgers contributed to conception of the study, interpretation of the results, editing successive drafts of the paper and final approval of the version to be published. Patricia 
Jacomb was responsible for the data collection. Karen Maxwell was responsible for the implementation of the study and data collection.

\section{Authors' affiliations}

R M D'Souza, L Strazdins, L L-Y Lim, D H Broom, National Centre for Epidemiology and Population Health, Australian National University, Canberra, Australia

B Rodgers, Centre for Mental Health Research, Australian National University

Funding: funding for this study was provided by a unit grant (no 973302) and new program grant (no 179805) from the National Health and Medical Research Council, and additional support from the Australian Rotary Health Research Fund and the Australian Brewers' Foundation Medical Research Grant Scheme.

\section{REFERENCES}

1 Karasek RA. Job demands, job decision latitude, and mental strain: implications for job design. Admin Sci Q 1979;24:285-309.

2 Bosma $H$, Marmot MG, Hemingway $H$, et al. Low job control and risk of coronary heart disease in Whitehall II (prospective cohort) study. BMJ 1997:314:558-65.

3 Cheng Y, Kawachi I, Coakley EH, et al. Association between psychosocial work characteristics and health functioning in American women: prospective study. BMJ 2000;320:1432-6.

4 Theorell T. Working conditions and health. In: Berkman LF, Kawachi I, eds. Social epidemiology. Oxford: Oxford University Press, 2000:95-117.

5 Marmot MG, Bosma H, Hemingway $\mathrm{H}$, et al. Contribution of job control and other risk factors to social variations in coronary heart disease incidence. Lancet 1997:350:235-9.

6 Stansfeld SA, Fuhrer R, Head J, et al. Work and psychiatric disorder in the Whitehall II Study. J Psychosom Res 1997;43:73-81

7 Amick BC 3rd, Kawachi I, Coakley EH, et al. Relationship of job strain and isostrain to health status in a cohort of women in the United States. Scand J Work Environ Health 1998;24:54-61

8 Marmot M, Siegrist J, Theorell T, et al. Health and the psychosocial environment at work. In: Marmot M, Wilkinson RG, eds. Social determinants of health. Oxford: Oxford University Press, 1999:105-31.

9 Australian Bureau of Statistics. Casual employment. Labour Force, Australia 1999, July (ABS catalogue Number 6203.0). Canberra: Australian Bureau of Statistics, 1999.

10 Kuhnert K. The relationship between job security and employee health. Group and Organisation Studies 1989;14:399-410.
11 Roskies E, Louis-Guerin C, Fournier C. Coping with job insecurity: how does personality make a difference? Journal of Organizational Behavior 1993;14:617-30.

12 McDonough P. Job insecurity and health. Int J Health Serv 2000;30:453-76.

13 Kivimaki M, Vahtera J, Pentti J, et al. Factors underlying the effect of organisational downsizing on health of employees: longitudinal cohort study. BMJ 2000;320:971-5.

14 Ferrie JE, Shipley MJ, Marmot MG, et al. An uncertain future: the health effects of threats to employment security in white-collar men and women. Am J Public Health 1998;88:1030-6.

15 Ferrie JE, Shipley MJ, Marmot MG, et al. The health effects of major organisational change and job insecurity. Soc Sci Med 1998;46:243-54.

16 Australian Bureau of Statistics. Australian standard classification of occupations, (ASCO) 2nd edn. (ABS Catalogue Number 1220.0). Canberra: Australian Bureau of Statistics, 1997.

17 Goldberg D, Bridges K, Duncan-Jones $P$, et al. Detecting anxiety and depression in general medical settings. BMJ 1988;297:897-9.

18 Ware JE, Kosinski M, Keller SD. A 12-item short-form health survey. Med Care 1996:34:220-33.

19 Gandek B, Ware JE, Aaronson NK, et al. Cross-validation of item selection and scoring for the SF-12 health survey in nine countries: results from the IQOLA Project. International quality of life assessment. J Clin Epidemiol 1998:51:1171-8.

20 Spector $\mathrm{PE}, \mathrm{O}^{\prime}$ onnell $\mathrm{BJ}$. The contribution of personality traits, negative affectivity, locus of control and Type A to the subsequent reports of job stressors and job strains. J Occup Organ Psychol 1994;67:1-11.

21 Carver C, White T. Behavioral inhibition, behavioral activation, and affective responses to impending reward and punishment: the BIS/BAS scales. Journal of Personality and Social Psychology 1994;67:319-33.

22 Jorm AF, Christensen $\mathrm{H}$, Hendersen AS, et al. Using the BIS/BAS scales to measure behavioural inhibition and behavioural activation: factor structure, validity and norms in a large community sample. Personality and Individual Differences 1999;26:49-58.

23 Johnson JV, Stewart WF. Measuring work organization exposure over the life course with a job-exposure matrix. Scand I Work Environ Health 1993; 19:21-8.

24 North FM, Syme SL, Feeney A, et al. Psychosocial work environment and sickness absence among British civil servants: the Whitehall II study. Am J Public Health 1996;86:332-40.

25 Kivimaki M, Vahtera J, Thomson L, et al. Psychosocial factors predicting employee sickness absence during economic decline. J Appl Psychol 1997:82:858-72.

26 Mathers C, Vos T, Stevenson C. The burden of disease and injury in Australiasummary report. Canberra: Australian Institute of Health and Welfare, 1999:31. 